\title{
Fungi in bottled water: A case study of a production plant
}

Ana Ribeiro ${ }^{1,2}$, A. Patrícia Machado ${ }^{1,2}$, Zofia Kozakiewicz ${ }^{3}$, Matthew Ryan ${ }^{3}$, Belinda Luke ${ }^{3}$, Alan G. Buddie ${ }^{3}$, Armando Venâncio ${ }^{1}$, Nelson Lima ${ }^{1,2}$ and Joan Kelley ${ }^{3}$

${ }^{\prime}$ Centro de Engenharia Biológica and ${ }^{2}$ Micoteca da Universidade do Minho, Universidade do Minho, Braga, Portugal; ${ }^{3}$ CAB International, Egham, Surrey, United Kingdom

Summary A one-year fungal survey of a water bottling plant was conducted in order to evaluate the incidence and fluctuations of the mycobiota. The dominant fungal genera in order of highest numbers isolated were Penicillium, Cladosporium and Trichoderma followed by Aspergillus, Paecilomyces, and others. As expected, the highest number of isolates were collected during the warmer months, particularly May and June. Indeed during these two months there were more fungi present in the water, indicating that during those times of the year when fungal contamination is high, $0.4 \mu \mathrm{m}$ filters should be changed on a more regular basis. In order to assess whether contamination was single or multi-loci, molecular methods based on the PCR were used for Penicillium brevicompactum. Overall, fungal contamination arose from multiple sources. Some P. brevicompactum strains were very "alike" and were detected during different sampling times, indicating that they were endemic to the plant. There was no evidence to suggest that fungi detected in the source water passed through to other parts of the plant. However, there was evidence that fungal strains isolated from the water filter were detected elsewhere in the factory, confirming the need to change filters more regularly during periods of high fungal contamination. In order to improve quality control a HACCP programme was implemented and Best Practice Guidelines introduced.

Key words Bottled water, Fungal survey, Penicillium brevicompactum, Cladosporium, Trichoderma, PCR

There is little information available regarding the detection and isolation of fungi from drinking and bottled waters $[3,15,17]$. Literature surveys undertaken [9] indicate that most studies have been a reaction to contamination events rather than the result of a concerted study. Furthermore most quality control programmes within water bottling plants have been more concerned with bacterial (particularly of faecal origin) rather than fungal and yeast contaminations [1]. For these reasons this one year project was undertaken to study and control fungal contamination within a Portuguese water bottling factory in order to develop standard methodologies to isolate and enumerate fungi within this arena. The reason being that if fungi were to be included as routine in water analyses then the requirement for additional equipment could be kept to a minimum. Furthermore, in order to satisfy all of the European

Corresponding address:

Zofia Kozakiewicz

CAB International, Bakeham Lane

Egham, Surrey TW20 9TY, United Kingdom

Tel.: +44 1491829061

E-mail: Griffithsacari@aol.com

(2006 Revista Iberoamericana de Micología

Apdo. 699, E-48080 Bilbao (Spain)
$1130-1406 / 01 / 10.00$
Union Directives concerning Drinking Water [Council Directive 98/83/ EC of $3^{\text {rd }}$ November 1998 on the quality of water intended for human consumption; Directive 75/440/EEC; Council Directive 80/778/EEC], best practice guidelines and a HACCP system were also established.

As part of the present study PCR, fingerprinting techniques were used to assess whether the contamination was from one source or multi-loci. Such techniques have been applied to filamentous fungi for nearly 20 years and have been used to provide solutions for a plethora of mycological problems ranging from analysis of geographic distribution $[4,11]$, to pathogenicity assessments [13] and population studies [5]. Techniques are available that allow for discrimination between and within species, but reproducibility of PCR techniques especially those using RAPD-PCR (Random Amplified Polymorphic DNA) [24] is not consistent. Minor variations in PCR conditions can result in the production of widely differing banding patterns [12], making reproducibility extremely difficult, especially between laboratories where reagents and equipment will differ.

However, VNTR (Variable Nucleotide Random Repeat), AP (Arbitrarily Promed) [5] and ISSR (Inter Simple Sequence Repeat) [7] PCR techniques are more stringent and reproducible. These techniques were used in this study because they allow for an assessment of a larger number of isolates than would be possible using more technically complex methodologies such as AFLP which would not necessarily have provided more detailed information. 
Therefore, the aims of this study were to analyse the seasonal fluctuations of fungal contamination and trace the origin of contaminating fungal populations with molecular biology techniques in a bottled water company.

\section{Materials and methods}

Sampling dates. Samples were taken twice monthly from May to September 2003 and on a monthly basis from October 2003 to April 2004.

Samples. Water samples (1 1 each) were taken from three water sources (water spring, bore holes H2 \& H8), the water tank (= before filtration), the water filler (= after filtration) and the bottled water (= end product).

Samples of caps from the glass and PET bottles were collected. These were plated directly onto malt extract agar (MEA [23]) and incubated in the dark, at $25^{\circ} \mathrm{C}$, for seven days. Colonies were counted and plated onto MEA for further identification.

Glass bottles were taken at the washer inlet and outlet. Each bottle was rinsed with $50 \mathrm{ml}$ of distilled water. This wash water was diluted into serial dilutions $\left(10^{0}, 10^{-1}\right.$, $10^{-2}, 10^{-3}$, etc.) and then spread plated onto selective media (NGRBA: neopeptone $5 \mathrm{~g} / \mathrm{l}$, glucose $10 \mathrm{~g} / \mathrm{l}$, Rose Bengal $3.5 \mathrm{ml}(1 \% \mathrm{w} / \mathrm{v})$, Aureomycin ${ }^{\circledast} 14 \mathrm{ml}(0.25 \% \mathrm{w} / \mathrm{v})$ and $20 \mathrm{~g} / \mathrm{l}$ agar; CMA1/2: corn meal extract $1 \mathrm{~g} / \mathrm{l}$ and $15 \mathrm{~g} / \mathrm{l}$ agar; YMG: yeast extract $3 \mathrm{~g} / \mathrm{l}$, malt extrat $3 \mathrm{~g} / \mathrm{l}$, peptone $5 \mathrm{~g} / \mathrm{l}$, glucose $10 \mathrm{~g} / \mathrm{l}$ and agar $20 \mathrm{~g} / \mathrm{l}$ ) and incubated in the dark at $25{ }^{\circ} \mathrm{C}$ for seven days. Colonies were counted and the fungal isolates plated onto MEA for isolation and identification to genus. Selected colonies were transferred to Czapek Dox agar (CZ [23]) for penicillia and aspergilli and Potato Carrot Agar (PCA [23]) for cladosporia and trichodermas) for identification to species level.

Swabs were periodically taken from the pipework at the filler outlet. They were then washed in sterile distilled water, and the suspension plated directly onto selective media (as above), and incubated at $25^{\circ} \mathrm{C}$ for 7 days. Colonies were counted and plated onto MEA for further identification.

Air samples (50 1) in duplicate were taken in the PET bottle storage area and the bottling room. A flow chart of the bottling plant is provided in figure 1 .

Baiting. This was undertaken on a monthly basis. Sterile pieces of cellophane $0.5 \mathrm{~cm}^{2}$ were placed into $1 \mathrm{l}$ bottled water. For this, two and three bottles of 0.51 and 0.331 were combined, respectively. The samples were incubated for seven days at $25^{\circ} \mathrm{C}$ in the laboratory with a day and night cycle. The baits were removed aseptically and plated directly onto selective media (NGRBA, CMA1/2, YMG) for a further seven days at $25^{\circ} \mathrm{C}$. The fungal colonies were counted and plated onto MEA for identification to genus.

Air sampling. Air sampling was carried out using an AirTEST-Omega device (L.C.A., France) which is based on the impaction method. Fifty litres of air in duplicate were sampled directly onto Dichloran Rose-Bengal

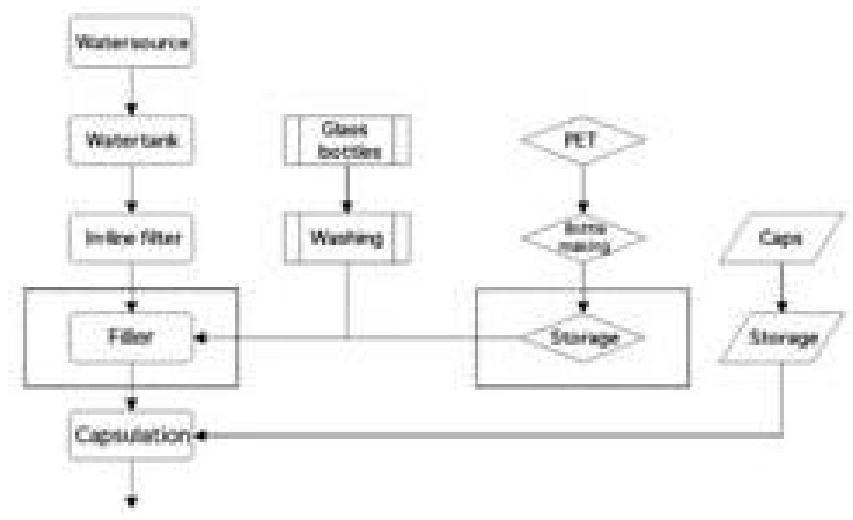

Figure 1. Flow chart of the bottling plant for the identification of sampling points.

Chloramphenicol Agar (DRBC: Oxoid CM727) plates. The plates were incubated in the dark at $25^{\circ} \mathrm{C}$ for seven days and the number of colonies counted.

Fungal isolates. Not all sampling dates had the same number of samples taken, as certain parts of the factory were only in operation on an ad hoc basis. The strains were categorised into major genera and their location within the factory noted. A database was created to collect the relevant strain information.

Identification of Penicillium, Aspergillus, and related genera. The isolates were three-point inoculated onto diagnostic media. For aspergilli, penicillia and Talaromyces these were Czapek Dox (CZ) agar and $4 \%$ malt extract $+\mathrm{CZ}$ agar $(\mathrm{M}+\mathrm{CZ})$, incubated at $25{ }^{\circ} \mathrm{C}$ in the dark for one week (two weeks for Talaromyces). For Eurotium isolates were again three-point inoculated onto malt plus $20 \%$ sucrose agar $(\mathrm{M}+20 \%)$ and incubated at $25^{\circ} \mathrm{C}$ for two weeks, whilst for Paecilomyces, isolates were single point inoculated onto PCA and placed under black light (UV-light) for five days. Isolates were identified to species according to the literature [18,20,21].

Identification of Cladosporium. The isolates were single point inoculated onto PCA and incubated at $25^{\circ} \mathrm{C}$ for seven days, and identified to species level where possible.

DNA extraction. A $1 \mathrm{~cm}^{2}$ block of mycelium and agar from the fungi grown on Malt agar, was chopped and used to inoculate $60 \mathrm{ml}$ Glucose-Yeast medium [GYM; 13] in $250 \mathrm{ml}$ glass conical flasks. These were incubated at $30{ }^{\circ} \mathrm{C}$ on an orbital shaker at $180 \mathrm{rpm}$ for seven days. The mycelium was collected and prepared for DNA extraction [16]. DNA was extracted using an adaptation of the CTAB method [6].

PCR conditions. DNA samples were diluted by 1:50 or 1:100 in TE buffer or $\mathrm{H}_{2} \mathrm{O}$ [16] according to the quality and concentration (determined from the results of a preliminary mini-gel run using dilutions of 1:100 or 1:50). The four primers used in this study are detailed in table 1. For ISSR-PCR (CCA primer [8]) the PCR mixture contai-

Table 1. Primers used in this study.

\begin{tabular}{lll}
\hline Name & Origin & Sequence \\
\hline BOXA1R & Conserved repeated DNA element from Streptococcus pneumoniae & CTACGGCAAGGCGACGCTGACG \\
CCA & ISSR (Inter-Simple Sequence Repeat) primer & DDB(CCA) 5 \\
ERIC 1 & Enterobacterial Repetitive Intergenic Consensus sequences & ATGTAAGCTCCTGGGGATTCAC \\
MR & M13 Phage core consensus & AGGGTGGCGGTTCT
\end{tabular}


ned $2 \mu$ Primer solution (Sigma Genosys, UK), 2 ul 125 nM each of dNTP's (Pharmacia Biotech, UK), $12.875 \mu l$ sterile HPLC water (BDH Ltd., UK), $0.125 \mu \mathrm{l}$ (0.75 units) Super Tth enzyme (HT Biotechnology Ltd., UK), 2 ul PCR buffer (HT Biotechnology Ltd., UK) and 1 ul of diluted template DNA. The PCR was carried out in a PCR Express thermocycler (Hybaid, UK). The PCR programme used was 2 min at $94^{\circ} \mathrm{C}, 35$ cycles of $1 \mathrm{~min}$ at $94{ }^{\circ} \mathrm{C}$, $2 \mathrm{~min}$ at $53{ }^{\circ} \mathrm{C}$ and $2 \mathrm{~min}$ at $72{ }^{\circ} \mathrm{C}$ followed by a completion stage of $10 \mathrm{~min}$ at $72{ }^{\circ} \mathrm{C}$ and then cooled to $4{ }^{\circ} \mathrm{C}$.

For all other PCR processes the PCR mixture contained $5 \mu \mathrm{l}$ of $50 \mathrm{nmol}$ primer solution, $4 \mu \mathrm{l}$ (2.5 mM each) dNTPs, 31.75 ul HPLC water, 3 ul (1.875 nmole) $\mathrm{MgCl}_{2}$, (Sigma), $5 \mu \mathrm{l}$ Tth reaction buffer (HT Biotechnology Ltd., UK), $0.25 \mathrm{ul}$ (1.25 units) Super Tth Enzyme and 1 ul of diluted template DNA. A control was set up with $1 \mu \mathrm{l}$ sterile water in place of template. The PCR programme used consisted of an initial denaturation at $95^{\circ} \mathrm{C}$ for $5 \mathrm{~min}$, followed by 35 cycles each consisting of a denaturation step at $95^{\circ} \mathrm{C}$ for $30 \mathrm{sec}$, an annealing step at $42{ }^{\circ} \mathrm{C}$ for 30 sec, an extension step at $72{ }^{\circ} \mathrm{C}$ for $90 \mathrm{sec}$, followed by a final extension step at $72{ }^{\circ} \mathrm{C}$ for $10 \mathrm{~min}$ after the last cycle. Samples were transferred to a freezer at $-20{ }^{\circ} \mathrm{C}$ for storage. Gel electrophoresis. PCR products were separated on a $1.5 \%(w / v)$ LE agarose (Seakem, FMC Bioproducts, UK) gel prepared with Tris-acetate EDTA buffer [TAE; 15]. A 15 x $10 \mathrm{~cm}$ midi-gel tank (ATTO, Japan) was used with a 20 well capacity comb set into the gel which was submerged in TAE before $20 \mu$ of PCR product from each replicate was mixed with $5 \mu$ of loading buffer and loaded into the gel. Size markers were prepared using $8 \mu \mathrm{l}$ 100 bp ladder (GIBCO BRL, Life Technologies Ltd., UK) solution (diluted 1:19 in water) and $4 \mu \mathrm{l}$ stop solution. The gel was run at $5 \mathrm{~V} \mathrm{~cm}^{-1}$ for approx $2 \mathrm{~h}$. The gel was then stained with ethidium bromide (Sigma, UK) solution $\left(0.5 \mathrm{ug} \mathrm{ml}^{-1}\right.$ in water) for $30 \mathrm{~min}$. Gels were viewed in a UV transilluminator (UVP, UK) and captured electronically using UVP imaging equipment.

Gel analysis. Gels were visually assessed. Gel images obtained with MR primer (the universal fingerprinting primer) were saved in the TIFF file format and were loaded into GelCompar 11 software (Applied Maths BVBA, Sint-Martens-Latem, Belgium). Gels were analysed and a dendrogram produced.

\section{Results and discussion}

Fungi. A total of 604 strains were isolated from the bottling plant. There was a gradual increase in fungal bioload during May with a peak in early June. On this and subsequent sampling dates the proportion of strains isolated represented $50 \%$ penicillia, 30\% cladosporia and $20 \%$ other genera. This high peak of fungal bioload (May-June) coincided with a similar high bioload for the water source, water tank and water filler. The fact that counts for the water filler were high is cause for concern as the water had been through a particulate filter $(0.4 \mu \mathrm{m})$ at this point. Interestingly, fungal counts had dropped considerably for the second June sampling, which coincided with a change of filter. This highlights the need to change filters on a regular basis particularly during high fungal bioloads such as during the warmer months. Otherwise, there is a chance that fungi caught in the filter not only clog it up and make it ineffective, but also fungal mycelium could start to grow through the filter and sporulate on the "clean" side with spores being passed on down the line. Sampling of glass bottles before and after rinsing highlighted the efficacy of the washing process. On five separate occasions glass bottles had a higher fungal count after washing than before. Furthermore, some of the fungal species isolated after washing were not present before washing. This indicates the need to change the wash-water on a more frequent basis, and a need to handle the "clean" bottles in a more hygienic manner. Recommendations were made to reassess the washing procedures at the plant.

Fungi were isolated from the final product (water) on every date sampled. Furthermore, fungal counts were high in PET bottles during May and June, coinciding with a high bioload overall. But for most other sampling dates there was little difference between glass and PET bottles. Similarly, swabs taken from the water filler outlet and sampled caps yielded very low counts.

The dominant penicillia isolated throughout the plant and on most sampling dates were Penicillium brevicompactum and Penicillium glabrum, followed by Penicillium chrysogenum (Table 2). All three species are common indoor contaminants. P. brevicompactum and $P$. chrysogenum are xerophilic penicillia, that is, able to grow on substrates containing very little free water, hence their frequenct occurance in indoor environments.

Penicillium expansum was prevalent through the sampling sites (water source, water tank, water filler, bottles, air) during the first sampling (May) but then only appeared intermittently in isolated loci later (Table 2). $P$. expansum is a soil organism requiring higher water activities than $P$. brevicompactum and $P$. chrysogenum for growth [19]. This would explain its less frequent isolation once the temperatures increased for high summer.

Three other penicillia were isolated less frequently, namely Penicillium aurantiogriseum, Penicillium corylophilum and Penicillium roqueforti. Both P. aurantiogriseum and $P$. corylophilum are common contaminants and frequently isolated in indoor environments. $P$. roquefort $i$ has an ability to grow under conditions of low oxygen. The fact that it was isolated from the bottles could be problematic.

Aspergillus versicolor a species commonly isolated from paint and wood-work, was most prevalent in the bottling room. It was also isolated from caps and occasionally bottles.

Several species considered to be more tropical in origin were isolated during the summer months and early autumn. These were Aspergillus niger, Penicillium pinophilum, $P$. islandicum, $P$. minioluteum and $P$. purpurogenum. Both $A$. niger and $P$. pinophilum were isolated from the water source, and the tank. A. niger was previously isolated from mains water distribution systems where it produced off-flavours and taints [2]. Fungi characterised by dark hyphae and spores, which contain melanin, such as $A$. niger and the cladosporia, are resistant to sunlight and water treatments. Interesting, $A$. niger was isolated during the latter stages of the bottled water storage studies, which indicates a considerable lag-phase before this particular species becomes problematic.

The two dominant cladosporia found throughout the site were Cladosporium cladosporioides and Cladosporium sphaerospermum (Table 3 ). C. cladosporioides is the most ubiquitous of the genus, occurring in soil and plant material. Since the bottling plant is sited in a wooded valley, this is probably the source of contamination. Spores of $C$. cladosporioides are frequently air-borne, and this coincides with high numbers for this species during the summer month samplings.

C. sphaerospermum is more xerophilic, able to grow slowly at water activities of 0.81 [19]. It is commonly isolated in indoor environments. In addition, it is a 
Table 2. Fungal bioload of Paecilomyces, Aspergillus, Penicillium and related genera throughout the water bottling plant.

\begin{tabular}{|c|c|c|c|c|c|c|c|c|c|c|c|}
\hline Taxon & Water source & Water tank & $\begin{array}{l}\text { Water } \\
\text { filler }\end{array}$ & Water bottles & Caps & $\begin{array}{l}\text { Bottle } \\
\text { inlet }\end{array}$ & $\begin{array}{l}\text { Bottle } \\
\text { outlet }\end{array}$ & Air PET & Air room & $\begin{array}{l}\text { Water } \\
\mathrm{H} 8\end{array}$ & Swab \\
\hline \multicolumn{12}{|l|}{ Aspergillus } \\
\hline A. niger & $\mathrm{L}$ & $\mathrm{D}$ & & & I & & JK & & & & \\
\hline A. sydowii & & & & & & & $\mathrm{P}$ & & & & \\
\hline A. ustus & & & & $\mathrm{K}$ & & & & & & & \\
\hline A. versicolor & & & & & EJ & & $\mathrm{B}$ & $\mathrm{BL}$ & BHMP & & \\
\hline \multicolumn{12}{|l|}{ Eurotium } \\
\hline E. amstelodami & & & & & & & & $\mathrm{K}$ & & & \\
\hline \multicolumn{12}{|l|}{ Paecilomyces } \\
\hline P. lilacinus & & & & & CJ & & & & I & $\mathrm{K}$ & \\
\hline P. variotii & & & & & & & & & $\mathrm{J}$ & & \\
\hline \multicolumn{12}{|l|}{ Penicillium } \\
\hline P. atramentosum & & & & & & & & & $\mathrm{J}$ & & \\
\hline P. aurantiogriseum & $\mathrm{C}$ & CJ & & $\mathrm{F}$ & $\mathrm{BGHO}$ & & & $\mathrm{DHO}$ & & $\mathrm{P}$ & $\mathrm{P}$ \\
\hline P. brevicompactum & CDEGHLP & BCEGH & BCDN & ABCDEFHKMN & ABCDEGM & $\mathrm{AC}$ & BEO & ACELM & ABCDILO & FGJ & $E$ \\
\hline P. camemberti & $\mathrm{L}$ & & & & & & & & & & \\
\hline P. chrysogenum & BEFL & DFG & FGM & DEFHLP & ADFGHO & $\mathrm{AHIO}$ & $P$ & DJ & $\mathrm{HI}$ & $\mathrm{FI}$ & \\
\hline P. citrinum & $\mathrm{BL}$ & & & & A & & & $\mathrm{O}$ & & $\mathrm{KL}$ & L \\
\hline P. commune & & C & & & & & & & & & \\
\hline P. corylophilum & $\mathrm{C}$ & $\mathrm{BC}$ & 1 & ABGI & CDHLNP & & & ELO & CIJM & & \\
\hline P. crustosum & CDG & & $G$ & IJ & FJ & & & $\mathrm{D}$ & & J & \\
\hline P. decumbens & $\mathrm{B}$ & & & & & & & & & & \\
\hline P. dendriticum & & & & & & & & & $J$ & & \\
\hline P. expansum & $\mathrm{ACL}$ & $\mathrm{AF}$ & $\mathrm{ACL}$ & ACDMO & $\mathrm{F}$ & $\mathrm{B}$ & & $\mathrm{KL}$ & $\mathrm{ACM}$ & EJ & \\
\hline P. funiculosum & $\mathrm{AE}$ & & & $\mathrm{BC}$ & $\mathrm{B}$ & & & $\mathrm{F}$ & $\mathrm{AF}$ & & \\
\hline P. glabrum & ABCEFHLNR & BCDEHIOR & BCFG & ABCDEFGHKLP & ABCDHMO & ABEHM & & ACDEGJLMN & ACFGIKNO & GK & \\
\hline P. glandicola & & I & & & & & & & & $\mathrm{H}$ & \\
\hline P. griseofulvum & & 10 & & & & A & & & & & \\
\hline$P$. islandicum & & & & & $A$ & & & & & & \\
\hline P. janthinellum & B & & $\mathrm{B}$ & & & & & & & & \\
\hline P. minioluteum & & & $\mathrm{B}$ & $\mathrm{HJ}$ & $A C$ & & A & & & $\mathrm{K}$ & \\
\hline P. paxilli & B & & $\mathrm{C}$ & $\mathrm{Cl}$ & $D$ & $\mathrm{C}$ & $\mathrm{E}$ & $\mathrm{CF}$ & & & \\
\hline P. pinophilum & $\mathrm{C}$ & $\mathrm{F}$ & & $A$ & & 1 & & & & & \\
\hline P. purpurogenum & & & & & & & & $\mathrm{C}$ & $\mathrm{C}$ & & \\
\hline P. roqueforti & $J$ & I & $\mathrm{BH}$ & EHJKM & $\mathrm{BI}$ & $\mathrm{C}$ & $\mathrm{L}$ & $\mathrm{N}$ & $\mathrm{N}$ & & $J$ \\
\hline P simplicissimum & $\mathrm{C}$ & & $\mathrm{C}$ & $\mathrm{F}$ & & & & & & $\mathrm{E}$ & \\
\hline P. spinolusum & $\mathrm{B}$ & & & $\mathrm{P}$ & & $\mathrm{B}$ & & & $\mathrm{ABJ}$ & & \\
\hline P. thomii & $\mathrm{C}$ & $\mathrm{F}$ & & & & & & & & & \\
\hline P. variabile & & $\mathrm{N}$ & $\mathrm{AC}$ & $A$ & HR & & & & $M$ & $\mathrm{~K}$ & \\
\hline P. verrucosum & & & & $\mathrm{G}$ & & & & & & & \\
\hline P. waksmanii & $M$ & $\mathrm{G}$ & & & $\mathrm{GH}$ & & & & & & \\
\hline \multicolumn{12}{|l|}{ Talaromyces } \\
\hline T. flavus & $\mathrm{C}$ & & & & & & & $J$ & & & \\
\hline$A=$ Collected $13 / 05 / 03$ & \multirow{6}{*}{\multicolumn{11}{|c|}{$\begin{array}{l}B=\text { Collected 27/05/03 } \\
E=\text { Collected } 08 / 07 / 03 \\
H=\text { Collected 26/08/03 } \\
K=\text { Collected 21/10/03 } \\
N=\text { Collected 13/01/04 } \\
R=\text { Collected 21/04/04 }\end{array}$}} \\
\hline $\mathrm{D}=$ Collected $26 / 06 / 03$ & & & & & & & & & & & \\
\hline $\mathrm{G}=$ Collected $01 / 08 / 03$ & & & & & & & & & & & \\
\hline $\mathrm{J}=$ Collected 30/09/03 & & & & & & & & & & & \\
\hline $\mathrm{M}=$ Collected $03 / 12 / 03$ & & & & & & & & & & & \\
\hline $\mathrm{P}=$ Collected $03 / 02 / 04$ & & & & & & & & & & & \\
\hline
\end{tabular}

common and cosmopolitan species occurring on many different substrates including plant material. Like C. cladosporioides it peaks in the warmer months.

Cladosporium herbarum was only isolated in May and September with one further occurrence (March 2004). Its lowest water activity for growth is 0.88 [19], which may account for its isolation during less arid months. It is a common species, worldwide in distribution, and is especially abundant in temperate regions on dead or dying plant substrates and other organic matter [22]. It is also isolated from soil and air.

Cladosporium oxysporum was found in low numbers throughout the plant. Like the other cladosporia, the source of contamination is likely to be the surrounding woodland and soil. Cladosporium asschycete, C. glandicola and $C$. tenuissimum were only isolated on one or two occasions during the whole year of sampling, and are therefore unlikely to be of major concern as contaminants. Molecular techniques. The molecular component of this project was used to confirm whether fungi isolated from the source water were distributed throughout the bottling plant and/or whether different fungal populations were appearing in discrete sites within the plant, thus indication contamination sources other than from the source water. If the same genotypes were found in consecutive sampling periods for the same site, this would indicate that the particular fungal colony was established and therefore the cleaning regime was not satisfactory.

DNA of suitable quality for PCR was extracted from 55 isolates of $P$. brevicompactum. P. brevicompactum was selected as it was the dominant organism found throughout the plant and at all sampling times. This PCR approach, of using a multimethod/primer, permitted a larger number of strains to be assessed than would be possible if a more complex methodology was used, but without compromising stringency and scientific validity.

Excellent results were obtained with ERIC and MR primers. Characteristic banding patterns were evident for $P$. brevicompactum. Sixteen to 20 bands were generated for each strain with MR primer and 16-18 bands with 
Table 3. Fungal bioload of Cladosporium isolates throughout the water-bottling factory.

\begin{tabular}{|c|c|c|c|c|c|c|c|c|c|c|c|}
\hline Species & $\begin{array}{l}\text { Water } \\
\text { source }\end{array}$ & Water tank & Water filler & $\begin{array}{l}\text { Water } \\
\text { bottles }\end{array}$ & Caps & $\begin{array}{l}\text { Bottle } \\
\text { inlet }\end{array}$ & $\begin{array}{l}\text { Bottle } \\
\text { outlet }\end{array}$ & Air PET & Air room & $\begin{array}{l}\text { Water } \\
\mathrm{H} 8\end{array}$ & Swab \\
\hline C. ascchycete & & $A$ & & & & & & & & & \\
\hline $\begin{array}{l}\text { C. cladosporioides } \\
\text { C. glandicola }\end{array}$ & BCDEGKL & CDEGHIN & BCDEFGIKM & BCEFGIJKL & BCDEFGL & $\mathrm{BHI}$ & AEHO & ACDEGIK & EFGHJKLP & $\begin{array}{l}\mathrm{GHJ} \\
\mathrm{H}\end{array}$ & NO \\
\hline C. herbarum & FJP & DFGIJ & ABDI & BCDGI & $\mathrm{F}$ & & & $E G$ & DG & $\mathrm{El}$ & \\
\hline C. oxysporum & $\mathrm{H}$ & $J$ & M & $\mathrm{AE}$ & 1 & I & & $\mathrm{C}$ & $\mathrm{N}$ & I & \\
\hline $\begin{array}{l}\text { C. sphaerospermum } \\
\text { C. tenuissimum }\end{array}$ & BCDEGKL & CELP & BCDEFGIKM & $\begin{array}{l}\text { ACO } \\
\text { A }\end{array}$ & BCDEGP & ABM & CEGN & $A B$ & $\mathrm{ABCH}$ & $\begin{array}{l}\text { GJ } \\
J\end{array}$ & $\mathrm{~N}$ \\
\hline $\begin{array}{l}A=\text { Collected } 13 / 05 / 03 \\
D=\text { Collected } 26 / 06 / 03 \\
G=\text { Collected } 01 / 08 / 03 \\
J=\text { Collected } 30 / 09 / 03 \\
M=\text { Collected } 03 / 12 / 03 \\
P=\text { Collected } 03 / 02 / 04\end{array}$ & \multicolumn{2}{|c|}{$\begin{array}{l}\mathrm{B}=\text { Collected } 27 / 05 / 03 \\
\mathrm{E}=\text { Collected } 08 / 07 / 03 \\
\mathrm{H}=\text { Collected } 26 / 08 / 03 \\
\mathrm{~K}=\text { Collected } 21 / 10 / 03 \\
\mathrm{~N}=\text { Collected } 13 / 01 / 04 \\
\mathrm{R}=\text { Collected } 21 / 04 / 04\end{array}$} & \multicolumn{2}{|c|}{$\begin{aligned} \mathrm{C} & =\text { Collected } 12 / 06 / 03 \\
\mathrm{~F} & =\text { Collected } 22 / 07 / 03 \\
\mathrm{I} & =\text { Collected } 09 / 09 / 03 \\
\mathrm{~L} & =\text { Collected } 11 / 11 / 03 \\
\mathrm{O} & =\text { Collected } 17 / 02 / 04\end{aligned}$} & & & & & & & \\
\hline
\end{tabular}

ERIC. PCR analysis with BOXA1R [10] and ISSR-CCA primers gave good banding patterns with many common bands between isolates, suggesting the correct characterisation of the $P$. brevicompactum isolates. For example, with the BOXA1R primer up to 20 bands were produced for each strain, with up to $80 \%$ homogeneity between isolates. However, the definition, that is clarity of bands, achieved with BOXA1R and ISSR-CCA was not as good as that achieved with ERIC and MR primers. But the

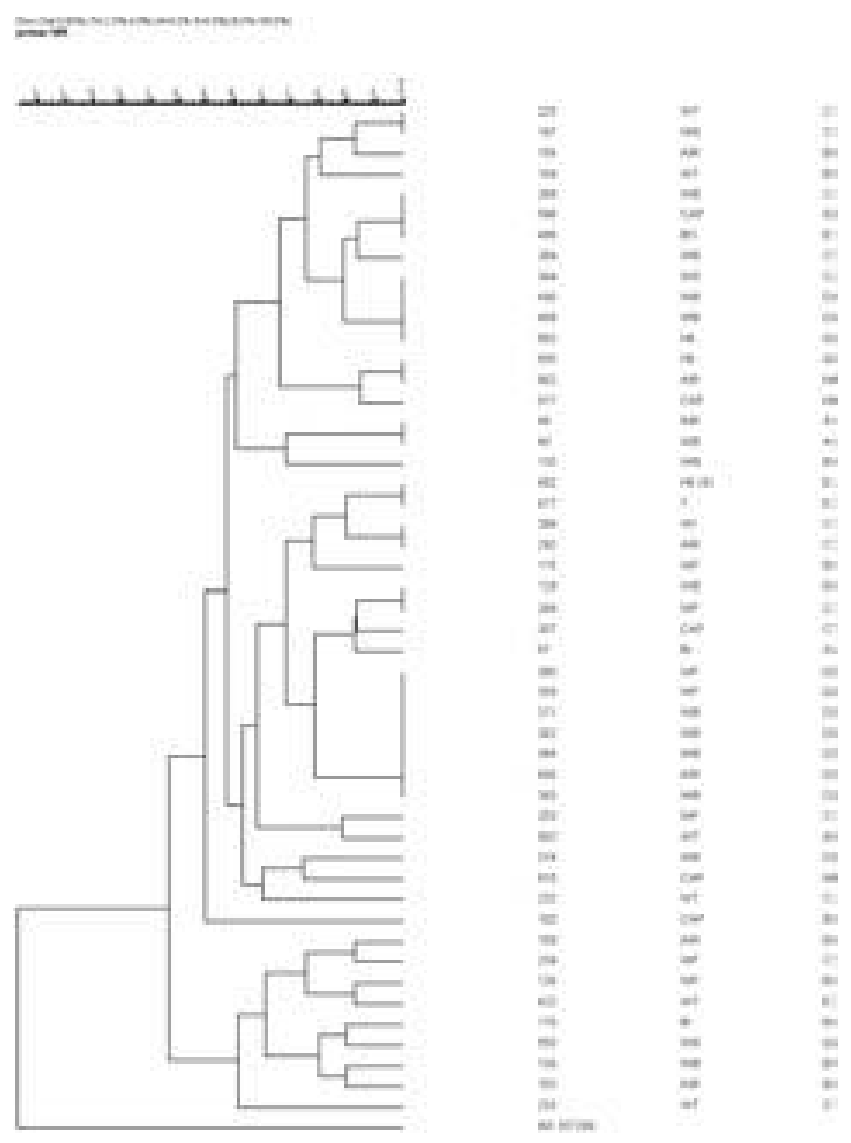

Figure 2. Cluster analysis of Penicillium brevicompactum cultures isolated from the water bottling facility over the course of the project. Dendrogram produced from PCR fingerprints generated with the MR 'universal

fingerprint' primer using Gelcompar II analytical software. Numbers, origin and date of studied strains are in the 3 columns, respectively. Strain IMI 357299 Penicillium expansum is an outgroup. AIR = Air PET (isolates 44 and 802)/Air room (the other isolates); $\mathrm{BI}=$ Bottle inlet; $\mathrm{BO}=$ Bottle outlet; $\mathrm{CAP}=\mathrm{Caps} ; \mathrm{H} 8=$ Water $\mathrm{H} 8$; WB $=$ Water bottles; WF $=$ Water filler;

WS $=$ Water source; WT $=$ Water tank; $?=$ Swab; $A=$ Collected 13/05/03; $\mathrm{B}=$ Collected 27/05/03; C = Collected 12/06/03; D = Collected 26/06/03 $\mathrm{E}=$ Collected $08 / 07 / 03 ; \mathrm{G}=$ Collected $01 / 08 / 03 ; \mathrm{M}=$ Collected $03 / 12 / 03$
ISSR-CCA and BOXA1R primers did generate fingerprints which were homogenous, that is few polymorphisms, which verified the taxonomy of the isolates. For these reasons, a cluster analysis was performed using MR primers since the PCR fingerprints generated exhibited slightly more intraspecific variability (Figure 2).

As with any statistical method, cluster analysis does have its limitations. For example, there may be groupings present which are purely artefacts of the results of the clustering process. Therefore, to assess the validity of the associations drawn from this dendrogram (Figure 2), a Principal Component Analysis (PCA) was applied with the same data set used to construct the dendrograms. This analysis suggested the general impression of a continuum with a few outlying strains. But there is a degree of variation within the overall group.

General assumptions that can be drawn from the dendrogram are that there are at least 32 distinct taxa of $P$. brevicompactum isolated in the plant, exhibiting $82.5 \%$ similarity. The dendrogram (Figure 2) suggests that 26 of the taxa can be assigned to one of ten groups consisting of between two and seven strains. This implies that the $P$. brevicompactum contamination within the bottling plant is multi rather than single locus, and that ingress of contamination is from sites other than the water source.

Isolates grouped as being $100 \%$ similar are isolates 40 and 44, both isolated in May (sampling time A) but from different sources, namely water bottle and air and, isolates 225 and 197 both isolated in June (sampling time C) but from water tank and water source respectively. This latter grouping is the one occasion where contamination in the source water was detected elsewhere in the plant.

At sampling time D (end of June) seven isolates were confirmed as being the same strain of $P$. brevicompactum. They were isolated throughout the factory from different locations namely, air, water filter and water bottles. This is direct evidence that contamination in the filter can be passed on to the final product. It also confirms the fungal counts findings, which at certain times of the year when the fungal bioload is high, filters become clogged and do not function correctly, spreading contamination. At such times filters should be changed more frequently.

Isolates 268, 466 and 596 are also identical, but were isolated at different sampling times $\mathrm{C}, \mathrm{E}$ and $\mathrm{G}$ (June, July and August) and from different locations (water bottle, bottle outlet and cap), suggesting that this particular strain was present continually in different areas of the plant, indicating that it may be endemic to the factory. The occurrence of identical strains appearing at different sampling times was also evidenced from isolates 129 and 248 collected from bottle and cap respectively in May and June. 


\section{Conclusions}

Fungi can be a difficult group of organisms to identify, and this is probably why their presence in bottled water has been ignored on the whole. However, the use of a range of media and isolation techniques (baiting, filtering) has permitted us to isolate and identify the diversity of fungi present in this habitat. The study has also highlighted the critical control points within the bottling plant, namely the need for regular filter changes, particularly during the warmer months when fungal bioload is high.

The molecular studies have shown that the contamination arises from multiple sources, in that different strains of $P$. brevicompactum appeared in discrete sites throughout the bottling plant. Only on one occasion was it evident that contamination in source water passed down the line. PCR also corroborated the need to change filters regularly, as well as changing wash water. The fact that identical isolates were isolated at different sampling times and from different locations suggests that some strains were endemic to the plant.

The problems highlighted in the plant were used to implement a HACCP programme and Best Practices guidelines for the Portuguese water bottling plant.

\section{References}

1. Anonymous. Guidelines for drinking water quality. Vol 1: Recommendations ( 2 nd $\mathrm{Ed}$ ) Guality. Vol W: Recommendations (2n Health Organisation, 1993.

2. Anonymous. The microbiology of water. Part 1: Drinking water, Report on Public Health and Medical Subjects No.71, Methods for the examination of waters and associated materials. London, $\mathrm{Her}$ Majesty's Stationery Office, 1994.

3. Bays LR, Burman NP, Lewis WM. Taste and odour in water supplies in Great Britain: a survey of the present position and problems for the future. Water Treat. Exam. 1970; 19: 136-160.

4. Bentley S, Pegg KG, Dale JL. Genetic variation among a world-wide collection of isolates of Fusarium oxysporum f.sp cubense analysed by RAPD-PCR fingerprinting. Mycol Res 1995; 99: 1378-1384.

5. Bridge PD, Pearce DA, Rivera A Rutherford MA. VNTR derived oligonucleotides as PCR primers for population studies in filamentous fungi. Lett Appl Microbiol 1997; 24: 426-430.

6. Cubero OF, Crespo A, Fatehi J, Bridge PD. DNA extraction and PCR amplification method suitable for fresh, herbarium-stored lichenized and other fungi. Plant Syst Evol 1999; 216: 243-249.

7. Grünig $C R$, Sieber TN, Holdenrieder $O$ Characterisation of dark septate fungi (DSE) using inter-simple-sequence-repeatanchored polymerase chain reaction (ISSR-PCR) amplification. Mycol Res 2001; 105: 24-32.

8. Hantula J, Dusabenyagasani M, Hamekin RC. Random amplified microsatellites (RAMS): A novel method for characterizing genetic variation within fungi. Eur J Plant Pathol 1996; 26: 159-166.
9. Kelley J, Hall G, Paterson RRM. The significance of fungi in water distribution systems. Report DW-01/F for UK Water Industry Research Limited. Egham, Industry Research Limited. Egham,
International Mycological Institute, 1997.

10. Koeuth T, Versalovic J, Lupski, JR. Differential subsequence conservation of interspersed repetitive Streptococcus pneumoniae BOX elements in diverse bacteria. Genome Res 1995; 5: 408-418.

11. Lodwig EM, Bridge PD, Rutherford MA, Kung'u J, Jeffries P. Molecular differences distinguish clonal lineages within East African populations of Fusarium oxysporum f.sp. cubense. J Appl Microbiol 1999; 86: 71-77.

12. MacPherson JM, Echstein PE, Scoles GJ, Gajadhar AA. Variability of the random amplified polymorphic DNA assay among thermocyclers, and effects of primer and DNA concentration. Mol Cell Probes 1993, 7: 293-299.

13. Maurer P, Couteaudier Y, Girard PA, Bridge PD, Riba G. Genetic diversity of Beauvaria bassiana (Bals.) Vuill. and relatedness to insect host range. Mycol Res 1997; insect host range $159-164$.

14. Mugnai L, Bridge PD, Evans HC. A chemotaxonomic evaluation of the genus Beauvaria. Mycol Res 1989; 199-209.

15. Nagy LA, Olson HB. The occurrence of filamentous fungi in drinking water distribution systems. Can J Microbio 1982; 28: 667-671.

16. Paterson RRM, Bridge PD. Biochemical techniques for filamentous fungi. In: Anonymous, IMI Technical Handbook No.1. Wallingford, CAB International, 1994: $55-70$.
The authors gratefully acknowledge the support of the EC, CRAFT programme, contract number: QLK1-2002-70843, Control of Mycological Contamination in Bottled Water (COMBOW), and to the Portuguese bottled water company for kindly permitting us to carry out this study.
17. Paterson RRM, Lima N. Fungal contamination of drinking water. In: Lehr $\mathrm{J}$, Keeley J, Lehr J, Kingery III TB (Eds.) Water Encyclopedia: Water quality control. Water Encyclopedia: Water quality 10.1002/047147844X.wq1516].

18. Pitt $\mathrm{JI}$. The genus Penicillium and its teleomorphic states Eupenicillium and Talaromyces. London, Academic Press, 1980.

19. Pitt Jl, Hocking AD. Fungi and food spoilage. London, Blackie Academic \& Professional, 1997.

20. Raper KB, Fennell DI. The genus Aspergillus. Baltimore, Williams and Wilkins, 1965

21. Samson RA. Paecilomyces and some allied Hyphomycetes. Stud Mycol 1974, No.6.

22. Samson RA, Hoekstra ES, Frisvad JC, Filtenborg O. Introduction to food-borne fungi. Baarn, Centraalbureau voor Schimmelcultures, 1995.

23. Smith D, Onions AHS. The preservation and maintenance of living fungi ( $2^{\text {nd }}$ Ed.) IMI Technical Handbooks No 2. Wallingford, CAB International, 1994: 1-93.

24. Toda T, Hyakumachi M, Arora DK. Genetic relatedness among and within different Rhizoctonia solani anastomosis groups as assessed by RAPD, ERIC and REP-PCR. Microbiol Res 1999; 154: 247-258. 